\title{
Investigation of Necessary Items for Garden Events to Revitalize Urban Communities
}

\author{
In-Kyoung Hong, Young Chae*, Sang-Mi Lee, and Young-Bin Jung \\ National Institute of Horticultural and Herbal Science, RDA, Wanju-gun 55365, Korea
}

\section{ABSTRACT}

This study is based on the premise that a garden space is a place that not only requires physical labor but also encourages conversation in the gardening group. We suggest the use of urban gardens as a place to revitalize local communities by promoting people to participate in various event programs. Through the theoretical study, we set the requirements that can be applied to "urban garden events". We developed measurement items and scales to be used as variables of each construction concept. Our survey was conducted on adults aged 19 and above who visited the 8th Korean Urban Agriculture Expo. Out of total 310 copies of the distributed questionnaire, only 298 effective samples were used in the empirical analysis. We can assume that people want to revitalize local communities based on the fact that 71 (23.8\%) participants said they thought the purpose of the event is to achieve unity among residents. Throughout analysis, 15 of the necessary items were confirmed and classified into two factors: image of event (Factor 1) and evaluation item (Factor 2). As a result of verifying the relationship between educational level for Factor 1, age was significant in five items and education level was significant in six items. For Factor 2, four items were effective in relation to education level, while significant results were not found in relation to age. These results are expected to be significant if the intellectual curiosity of the residents is satisfied and the demand base of the urban garden events according to the characteristics of city people is expanded. Based on this study, it is necessary to conduct research on the use of urban gardens as an event with social functions as well as various programs that can be carried out in gardens to build and revitalize the community.

Keywords: factor analysis, local festival, sustainability, sympathy, urban agriculture

\section{Introduction}

In the agrarian society of the past, there were spontaneous communities with a strong community spirit. However, as the urban concentration of population created a desolate external environment, poor communication among neighbors causes petty quarrels to turn into disputes, expanding into a social problem (Im, 2011). As such, to solve the social problems of cities, urban agriculture is actively developed as a means to achieve sustainable development (Kim et al., 2002). Urban agriculture, which began as a solution for foods that are safe to eat (Hong et al.,
2018), is rapidly expanding into a sound leisure activity and a community for city people exhausted by urban life, with the increased standard of living as well as their growing desire to enjoy leisure and relax in nature (Lee, 2013). Urban agriculture in Korea is also referred to as family gardens, allotment gardens, and vegetable gardens, and urban gardens where people can encounter nature from a close distance with family are receiving attention as an attractive element of urban life for city people (Kang et al., 2007). As urban agriculture receives great attention socio-culturally, urban gardens are perceived as an important method. According to the data by Korea Education and

This paper was funded by the Rural Development Administration as part of their project (PJ01260702).

Received: August 2, 2019, Revised: August 21, 2019, Accepted: September 17, 2019

First author: In Kyoung Hong, inkyoung63@korea.kr, (1) https://orcid.org/0000-0002-7050-5413

*Corresponding author: Young Chae, chaeyoung@korea.kr, (i) https://orcid.org/0000-0003-3378-6487 
Research Information Service (KERIS, http://www.riss.kr), even though there are as many as 340 studies on urban gardens, only 31 studies are conducted on urban gardens in terms of community revitalization. Moreover, there is no research that presented actual utilization plans of urban gardens for the purpose of community revitalization. Therefore, this study is conducted to suggest events to revitalize the community in terms of urban gardens. Accordingly, we studied the key items necessary for holding events and examined the relationship between age/education level and necessary items, for which the hypothesis is accepted, among many variables. The results of this study will contribute to active use of urban gardens as a venue for events.

\section{Research Methods}

\section{Subjects}

This study conducted a literature review on event-related types, characteristics, images, satisfaction and intention to recommend. For empirical research, we collected data from 310 male and female adults aged 19 and above who visited Cheongju Agricultural Technology Center where the 8th Korean Urban Agriculture Expo 2019 is held. The Urban Agriculture Expo is selected due to its benefit that there are many respondents of various types that are working or interested in agriculture and horticulture related to urban gardens, and also because it is in line with the intent of this study that must stimulate participants' curiosity and induce their participation with various activities in different fields during the event. Among 310 copies of the questionnaire distributed, 298 copies were ultimately used in the analysis excluding 12 copies that have many missing values or that are not fully responded.

\section{Questionnaire design}

\section{Composition of the survey}

The survey was composed of items such as demographic characteristics, purpose related to the event, expenditure, and necessary items, which were rated on the nominal scale and interval scale.

\section{Measurement items of the survey}

We came up with total 15 items necessary for events among event-related factors proposed by Kang (2003) (Table 1), and each item was rated on a 5-point Likert scale: 1 point 'strongly disagree', 2 points 'disagree', 3 points 'neutral', 4 points 'agree', and 5 points 'strongly agree'.

\section{Analysis method}

Statistical analysis was conducted using the IBM SPSS statistics 25 program after coding the collected questionnaire with the Excel program.

First, we conducted frequency analysis and technical analysis (based on the mean of the 5-point Likert scale) on items necessary for events and demographic characteristics of the subjects.

Second, to extract factors of necessary items for urban garden events, we conducted exploratory factor analysis and reliability analysis (Cronbach's a) to classify validity and factors of measured variables. Factor analysis was conducted using principal component analysis, extracting factors with varimax rotation among orthogonal rotations. Then we extracted only the factors with the eigenvalue of

Table 1. List of necessary item for successful garden event

\begin{tabular}{cll}
\hline Item $^{\mathrm{z}}$ & \multicolumn{1}{c}{ Factor } & Necessary item for garden event \\
\hline x1 & Playfulness & Things to enjoy \\
x2 & Playfulness & Things to see \\
x3 & Playfulness & Fun program \\
x4 & Experience & Cultural experience \\
x5 & Experience & New experience \\
x6 & Experience & Improving refinement \\
x7 & Locality & Enjoying local cultural color \\
x8 & Tradition & High historical value \\
x9 & Diversity & Many things to eat \\
x10 & Novelty & An event with family \\
x11 & Accessibility & Signposts \\
x12 & Accessibility & Event information \\
x13 & Environment & Kind event staff \\
x14 & Environment & Venue safety \\
x15 & Environment & Adequate amenities
\end{tabular}

${ }^{\mathrm{z}}$ Items were arbitrary variable name indicating the necessary items for garden event. 
1 or above and classified them. To verify the internal consistency of items, we conducted reliability analysis and calculated Cronbach'alpha coefficient, through which we verified the internal consistency of each factor.

Third, to determine the relationship between age/education level and necessary items for events for which the hypothesis is accepted among demographic variables, we conducted one-way ANOVA that is a statistical method used to verify the difference in the mean of samples. Then we used Duncan's multiple range test for the posttest and verified the relationship between the two variables set up as the hypothesis through regression analysis.

\section{Results and Discussion}

\section{Demographic characteristics}

Table 2 shows the demographic characteristics of the participants. There were total 298 participants, 217 women (72.8\%) and 81 men (27.2\%), with a remarkably higher ratio of women. 109 participants were in their $60 \mathrm{~s}(36.6 \%)$, followed by 96 in their 50s (32.2\%), 39 in their 40s (13.1\%), 36 in their $30 \mathrm{~s}(12.1 \%), 15$ in their $20 \mathrm{~s}(5.0 \%), 3$ under $20(1.0 \%)$, and none over 70 . This is because the survey was conducted at an exhibition venue and thus many visitors were families, schools or relevant organizations. By education level, 107 participants were middle or high school graduates $(35.9 \%)$, followed by 97 university graduates (32.6\%), 45 graduate students or higher (15.1\%), 37 2-year college graduates (12.4\%), and 12 below middle school

Table 2. Demographic characteristics of the respondents

\begin{tabular}{|c|c|c|c|c|c|}
\hline Item & $\mathrm{n}(\%)$ & Item & $\mathrm{n}(\%)$ & Item & $\mathrm{n}(\%)$ \\
\hline Gender & \multicolumn{2}{|r|}{ Occupation } & \multicolumn{3}{|c|}{ Average spending per event visit } \\
\hline Male & $81(27.2)$ & Student & $11(3.7)$ & Less than 50,000 won & 107(35.9) \\
\hline Female & $217(72.8)$ & Public official & $25(8.4)$ & $60,000-100,000$ won & $122(40.9)$ \\
\hline Total & $298(100.0)$ & Businessman & $20(6.7)$ & $110,000-200,000$ won & $36(12.1)$ \\
\hline Age & & Professional & $47(15.8)$ & $210,000-300,000$ won & $25(8.4)$ \\
\hline Under 20 & $3(1.0)$ & Self-employment & $33(11.1)$ & More than 300,000 won & $8(2.7)$ \\
\hline $21-30$ & $15(5.0)$ & Homemaker & $88(29.5)$ & Total & $298(100.0)$ \\
\hline $31-40$ & $36(12.1)$ & Agricultural organization & $44(14.8)$ & Event companion & \\
\hline $41-50$ & $39(13.1)$ & Others & $30(10.0)$ & Family or relatives & $116(38.9)$ \\
\hline $51-60$ & $96(32.2)$ & Total & $298(100.0)$ & Friends or colleagues & $110(36.9)$ \\
\hline Over 60 years old & $109(36.6)$ & Monthly income & & Neighbors & $16(5.4)$ \\
\hline Total & $298(100.0)$ & Less than 1 million won & $50(16.8)$ & Meetings or groups & $52(17.4)$ \\
\hline Education Level & & $1,000,000-1,990,000$ won & $56(18.8)$ & Others & $4(1.4)$ \\
\hline Below middle school & $12(4.0)$ & $2,000,000-2,990,000$ won & $83(27.9)$ & Total & $298(100.0)$ \\
\hline Middle or high school & $107(35.9)$ & $3,000,000-3,990,000$ won & $45(15.0)$ & Purpose of event & \\
\hline 2-year college & $37(12.4)$ & $4,000,000-4,990,000$ won & $25(8.4)$ & Unity among residents & $71(23.8)$ \\
\hline University & $97(32.6)$ & More than 5 million won & $39(13.1)$ & Industrial festival & $44(14.8)$ \\
\hline Graduate school or higher & $45(15.1)$ & Total & $298(100.0)$ & Special purpose & $11(3.7)$ \\
\hline \multirow[t]{6}{*}{ Total } & $298(100.0)$ & Residence & & Education participation & $60(20.1)$ \\
\hline & & Big city & $44(14.8)$ & Cultural welfare & $66(22.2)$ \\
\hline & & Small city & $202(67.8)$ & Tourism induction & $28(9.4)$ \\
\hline & & Farming or fishing village & $46(15.4)$ & Traditional festival & $18(6.0)$ \\
\hline & & Others & $6(2.0)$ & Total & $298(100.0)$ \\
\hline & & Total & $298(100.0)$ & & \\
\hline
\end{tabular}


(4.0\%). There were 88 homemakers $(29.5 \%)$, followed by 47 professionals $(15.8 \%), 44$ in agricultural organizations (14.8\%), 33 under self-employment (11.1\%), 30 others (10.0\%), 25 public officials $(8.4 \%), 20$ businessmen $(6.7 \%)$, and 11 students (3.7\%). For monthly income, 83 participants had an average monthly income of KRW 2-2.99 million (27.9\%), followed by 56 with KRW 1-1.99 million (18.8\%), 50 with less than KRW 1 million (16.8\%), 45 with KRW 3-3.99 million (15.0\%), 39 with KRW 5 million or more (13.1\%), and 25 with KRW 4-4.99 million (8.4\%). For residence, 202 participants lived in small cities (67.8\%), followed by 46 living in farming and fishing villages (15.4\%), 44 in big cities (14.8\%), and 6 in other places $(2.0 \%)$.

At the event, 122 participants responded that they spend KRW 60-100 thousand (40.9\%), followed by 107 spending less than KRW 50 thousand (35.9\%), 36 spending KRW 110-200 thousand (12.1\%), 25 spending KRW 210-300 thousand (8.4\%), and 8 spending more than KRW 300 thousand (2.7\%). Most of the participants spending more than KRW 300 thousand responded that they spend about KRW 500 thousand. For companion, 116 participants said they visit with family/relatives (38.9\%), followed by 110 visiting with friends/colleagues $(36.9 \%)$, 52 visiting in meetings/groups (17.4\%), 16 visiting with neighbors (5.4\%), and 4 with others (1.4\%). For the purpose of event, 71 participants chose unity among residents $(23.8 \%)$, followed by 66 choosing cultural welfare (22.2\%), 60 choosing education participation (20.1\%), 44 choosing industrial festival (14.8\%), 28 choosing tourism induction $(9.4 \%), 18$ choosing traditional festival $(6.0 \%)$, and 11 choosing special purpose (3.7\%).

\section{Factor analysis and reliability analysis on key items for events}

\section{Factor analysis on key items for events}

Table 3 shows the result of conducting a factor analysis by selecting the importance of events based on previous studies. KMO(Kaiser-Meyer-Olkin), the coefficient determining the sampling adequacy mentioned by Lee (2003), turned out to be .910 and the significance level was .000, providing the validity of factor analysis with a value close to 1 and a value exceeding 0.5 . Accordingly, the factors
Table 3. Factor analysis in necessary items for garden event

\begin{tabular}{|c|c|c|c|}
\hline \multirow{2}{*}{ Factor } & \multirow{2}{*}{ Item $^{\mathrm{z}}$} & \multicolumn{2}{|c|}{ Division } \\
\hline & & 1 & 2 \\
\hline \multirow{10}{*}{1} & $\mathrm{X} 5$ & .775 & .264 \\
\hline & X6 & .763 & .208 \\
\hline & $\mathrm{X} 8$ & .763 & .215 \\
\hline & $\mathrm{X} 4$ & .732 & .289 \\
\hline & $\mathrm{X} 7$ & .707 & .314 \\
\hline & $\mathrm{X} 10$ & .672 & .210 \\
\hline & X9 & .647 & .258 \\
\hline & $\mathrm{X} 3$ & .577 & .521 \\
\hline & $\mathrm{X} 2$ & .566 & .524 \\
\hline & $\mathrm{X} 1$ & .460 & .545 \\
\hline \multirow{5}{*}{2} & $\mathrm{X} 14$ & .175 & .823 \\
\hline & $\mathrm{X} 13$ & .188 & .801 \\
\hline & $\mathrm{X} 15$ & .305 & .749 \\
\hline & X11 & .294 & .746 \\
\hline & $\mathrm{X} 12$ & .351 & .743 \\
\hline \multicolumn{3}{|c|}{$\begin{array}{l}\text { Kaiser-Meyer-Olkin measure of } \\
\text { sampling adequacy }\end{array}$} & .910 \\
\hline \multirow{3}{*}{\multicolumn{2}{|c|}{ Bartlett's test of sphericity }} & $\chi^{2}$ & 2795.153 \\
\hline & & df & 105 \\
\hline & & Significant & .000 \\
\hline
\end{tabular}

${ }^{\mathrm{z}}$ Items were derived from Table 1.

are named image of event (Factor 1) and evaluation item (Factor 2) presented by Kang (2003) based on the commonality of items extracted. Factor 1 is named as 'image of event' factor, classifying importance as a factor with $\mathrm{x} 1$ (things to enjoy), $\mathrm{x} 2$ (things to see), $\mathrm{x} 3$ (fun programs), $\mathrm{x} 4$ (cultural experience), $\mathrm{x} 5$ (new experience), $\mathrm{x6}$ (improving refinement), $\mathrm{x} 7$ (enjoying local cultural color), $\mathrm{x} 8$ (high historical value), $\mathrm{x} 9$ (many things to eat), and $\mathrm{x} 10$ (an event with family). Factor 2 is named as 'evaluation item' factor with 5 items such as $\mathrm{x} 11$ (signposts), $\mathrm{x} 12$ (event information), x13(kind event staff), x14(venue safety), and x15(adequate amenities).

\section{Intemal consistency analysis by factor of key items for events}

Table 4 shows the result of reliability analysis conducted to determine the internal consistency by factor according to the results of factor classification. In all factors, Cronbach's 
Table 4. Reliability analysis in necessary items for garden event

\begin{tabular}{|c|c|c|c|c|}
\hline Factor & Item $^{\mathrm{z}}$ & $\begin{array}{c}\text { Revised } \\
\text { item-General } \\
\text { correlation }\end{array}$ & $\begin{array}{c}\text { Cronbach's } a \\
\text { if item } \\
\text { deleted }\end{array}$ & Cronbach's $a$ \\
\hline \multirow{10}{*}{1} & $\mathrm{X} 5$ & .740 & .899 & \multirow{10}{*}{.912} \\
\hline & X6 & .681 & .903 & \\
\hline & X8 & .705 & .902 & \\
\hline & $\mathrm{X} 4$ & .707 & .901 & \\
\hline & $\mathrm{X} 7$ & .701 & .902 & \\
\hline & $\mathrm{X} 10$ & .614 & .907 & \\
\hline & X9 & .625 & .907 & \\
\hline & X3 & .702 & .902 & \\
\hline & $\mathrm{X} 2$ & .703 & .902 & \\
\hline & $\mathrm{X} 1$ & .618 & .906 & \\
\hline \multirow{5}{*}{2} & $\mathrm{X} 14$ & .734 & .855 & \multirow{5}{*}{.882} \\
\hline & X13 & .704 & .860 & \\
\hline & $\mathrm{X} 15$ & .717 & .856 & \\
\hline & X11 & .715 & .859 & \\
\hline & $\mathrm{X} 12$ & .732 & .853 & \\
\hline
\end{tabular}

${ }^{\mathrm{z}}$ Items were derived from Table 1.

$a$, which is the internal consistency among activities, was .882-.912, showing a high level of internal consistency. With regard to internal consistency, Kang (2016) claimed that it is reliable when Cronbach's $a$ is .5 or higher, which indicates that key items for events are well structured. Moreover, Cronbach's $a$ when items are deleted tends to be lower than total Cronbach's $a$, which proves reliability as a measurement tool.

\section{Relational analysis by item of events and age/ education level among demographic variables}

To determine the relationship between necessary items for events and demographic characteristics, we examined the difference of each variable and verified the effects. Among demographic characteristics, the hypothesis was rejected in all items of income and residence and thus could not come up with results. Gender, which cannot be posteriori tested because there are two groups or less, and occupation, which has many samples indicating jobs before retirement, were excluded from analysis. For age and education level, there was a statistically significant difference in some items and thus relational analysis was conducted. We per- formed one-way ANOVA that is the statistical method verifying the difference in the means of samples to test the relationship, and used Duncan's multiple range test for posteriori test. To conduct a multiple regression analysis to test the causal relations between age/education level and necessary items for events, we classified the factors and set the necessary items for events as the dependent variables. For independent variables, we set six groups of age (age 20 and below [Group A], age 21-30 [Group B], age 31-40 [Group C], age 41-50 [Group D], age 51-60 [Group E], age 60 and above [Group F]) and five groups of education level (lower than middle school graduates [Group A], middle or high school graduates [Group B], 2-year college graduates [Group C]. university graduates [Group D], graduate school or higher [Group E]).

\section{Comparison of perception between age/education level variables and image of event (Factor 1)}

Tables 5 and 6 show the perception gap according to age/education level related to the image of event derived from factor analysis on necessary items for events by city people. Five items of image of event showed a statistically significant difference depending on age, such as 'new experience(x5)', 'enjoying local cultural color(x7)', 'fun programs(x3)', 'things to see( $\mathrm{x} 2)^{\prime}$ ', 'things to enjoy(x1), and six items depending on education level, such as 'new experience(x5)', 'cultural experience(x4)', 'enjoying local cultural color(x7)', 'fun programs(x3)', 'things to see(x2)', 'things to enjoy $(\mathrm{x} 1)$ '. For other items, there was no significant difference depending on age and education level.

By more specifically examining the items showing a significant difference depending on age, we could find out that the participants generally perceived new experience as 'important', and by age, Group A had a very positive perception about having a new experience with 5.00 , followed by Group C 4.44, Group B 4.40, Group D 4.26, Group E 4.09, and Group F 4.02. Overall, younger age groups had more positive perception about new experience.

The participants also perceived that enjoying local cultural color is 'important', with Group A having the most positive perception with 4.67, followed by Group C 4.36, Group B 4.33 Group D 4.15, Group F 3.88, and Group 
E 3.88. Overall, younger age groups had more positive perception about enjoying local cultural color. As for fun programs, the participants generally perceived them as 'average' or higher. Moreover, by age, Group A had the most positive perception on fun programs with 5.00, followed by Group B 4.73, Group C 4.31, Group D 3.95, Group E 3.86, and Group F 3.81. Overall, younger age groups had more positive perception about fun programs.

As for things to see at the event, the participants generally perceived them as 'important', and Group A had the most positive perception about things to see with 5.00 , followed by Group B 4.67, Group C 4.36, Group D 4.18, Group E 4.04, and Group F 3.96. They also perceived things to enjoy at the event as 'important' or higher, and Group

Table 5. Correlations between age and necessary items for garden event in Factor 1

\begin{tabular}{|c|c|c|c|c|c|c|c|c|}
\hline \multirow{2}{*}{ Item $^{\mathrm{z}}$} & \multicolumn{6}{|c|}{$\mathrm{Age}^{\mathrm{y}}$} & \multirow{2}{*}{$\mathrm{F}$} & \multirow{2}{*}{ Sig. } \\
\hline & A & B & $\mathrm{C}$ & $\mathrm{D}$ & $\mathrm{E}$ & $\mathrm{F}$ & & \\
\hline X5 & $5.00(0.00)$ & $4.40(0.74)$ & $4.44(0.65)$ & $4.26(0.85)$ & $4.09(0.86)$ & $4.02(0.99)$ & 2.288 & $.04 *$ \\
\hline X6 & $4.33(1.16)$ & $3.87(0.99)$ & $3.92(0.87)$ & $3.92(0.93)$ & $3.90(0.83)$ & $3.93(0.92)$ & 0.154 & $.98^{\mathrm{NS}}$ \\
\hline X8 & $4.00(1.00)$ & $3.40(0.91)$ & $3.53(0.85)$ & $3.56(1.05)$ & $3.68(0.94)$ & $3.67(1.07)$ & 0.434 & $.83^{\mathrm{NS}}$ \\
\hline $\mathrm{X} 4$ & $4.67(0.58)$ & $4.47(0.74)$ & $4.25(0.55)$ & $4.08(0.87)$ & $4.08(0.91)$ & $3.94(0.90)$ & 1.795 & $.11^{\mathrm{NS}}$ \\
\hline $\mathrm{X} 7$ & $4.67(0.58)$ & $4.33(0.73)$ & $4.36(0.93)$ & $4.15(0.99)$ & $3.88(0.90)$ & $3.95(0.91)$ & 2.445 & $.03^{*}$ \\
\hline $\mathrm{X} 10$ & $4.67(0.58)$ & $4.27(0.88)$ & $4.08(0.87)$ & $4.18(0.82)$ & $4.13(0.86)$ & $4.02(0.87)$ & 0.660 & $.65^{\mathrm{NS}}$ \\
\hline X9 & $4.67(0.58)$ & $3.93(0.88)$ & $3.94(0.89)$ & $3.62(0.99)$ & $3.64(0.95)$ & $3.61(1.09)$ & 1.446 & $.21^{\mathrm{NS}}$ \\
\hline $\mathrm{X} 3$ & $5.00(0.00)$ & $4.73(0.46)$ & $4.31(0.79)$ & $3.95(1.00)$ & $3.86(0.83)$ & $3.81(0.92)$ & 5.323 & $.000^{* * *}$ \\
\hline $\mathrm{X} 2$ & $5.00(0.00)$ & $4.67(0.49)$ & $4.36(0.68)$ & $4.18(0.94)$ & $4.04(0.79)$ & $3.96(0.85)$ & 3.752 & $.003 * *$ \\
\hline $\mathrm{X} 1$ & $5.00(0.00)$ & $4.60(0.63)$ & $4.44(0.61)$ & $4.13(0.80)$ & $4.09(0.87)$ & $3.85(0.84)$ & 5.231 & $.000 * * *$ \\
\hline
\end{tabular}

Note. Values are mean(standard deviation).

${ }^{\mathrm{z}} \mathrm{X} 5=$ new experience; $\mathrm{X} 6=$ improving refinement; $\mathrm{X} 8=$ high historical value; $\mathrm{X} 4=$ cultural experience; $\mathrm{X} 7=$ enjoying local cultural color; $\mathrm{X} 10=$ an event with family; $\mathrm{X} 9=$ many things to eat; $\mathrm{X} 3=$ =fun programs; $\mathrm{X} 2=$ things to see; $\mathrm{X} 1=$ things to enjoy.

${ }^{\mathrm{y}} \mathrm{A}=$ under 20; $\mathrm{B}=21-30 ; \mathrm{C}=31-40 ; \mathrm{D}=41-50 ; \mathrm{E}=51-60 ; \mathrm{F}=$ over 60 years old.

${ }^{\mathrm{NS}}$ Non-significant, ${ }^{*} p<.05,{ }^{* *} p<.01,{ }^{* * *} p<.001$ by ANOVA test.

Table 6. Correlations between education and necessary items for garden event in Factor 1

\begin{tabular}{|c|c|c|c|c|c|c|c|}
\hline \multirow{2}{*}{ Item $^{\mathrm{z}}$} & \multicolumn{5}{|c|}{ Education level $^{\mathrm{y}}$} & \multirow{2}{*}{$\mathrm{F}$} & \multirow{2}{*}{ Sig. } \\
\hline & A & B & $\mathrm{C}$ & $\mathrm{D}$ & $\mathrm{E}$ & & \\
\hline $\mathrm{X} 5$ & $4.25(1.22)$ & $3.97(0.94)$ & $4.00(0.97)$ & $4.21(0.82)$ & $4.58(0.58)$ & 4.249 & $.002 * *$ \\
\hline X6 & $4.00(0.85)$ & $3.88(0.93)$ & $3.59(0.87)$ & $4.01(0.86)$ & $4.05(0.83)$ & 1.825 & $.12^{\mathrm{NS}}$ \\
\hline X8 & $3.67(1.16)$ & $3.63(0.98)$ & $3.30(1.13)$ & $3.69(0.98)$ & $3.78(0.82)$ & 1.407 & $.23^{\mathrm{NS}}$ \\
\hline $\mathrm{X} 4$ & $4.17(0.94)$ & $3.93(0.96)$ & $3.86(0.92)$ & $4.16(0.76)$ & $4.38(0.65)$ & 3.135 & $.02 *$ \\
\hline $\mathrm{X} 7$ & $3.75(0.75)$ & $3.99(0.89)$ & $3.68(1.16)$ & $4.19(0.87)$ & $4.16(0.85)$ & 2.667 & $.03 *$ \\
\hline $\mathrm{X} 10$ & $4.17(0.84)$ & $3.96(0.96)$ & $4.03(0.76)$ & $4.15(0.76)$ & $4.36(0.83)$ & 1.904 & $.11^{\mathrm{NS}}$ \\
\hline X9 & $3.92(1.17)$ & $3.62(1.02)$ & $3.46(1.12)$ & $3.74(0.93)$ & $3.87(0.97)$ & 1.205 & $.31^{\mathrm{NS}}$ \\
\hline $\mathrm{X} 3$ & $3.83(1.03)$ & $3.77(0.91)$ & $3.81(1.02)$ & $4.12(0.83)$ & $4.24(0.74)$ & 3.630 & $.007 * *$ \\
\hline $\mathrm{X} 2$ & $4.17(0.94)$ & $3.93(0.83)$ & $3.92(0.95)$ & $4.28(0.72)$ & $4.33(0.80)$ & 3.803 & $.005^{* *}$ \\
\hline $\mathrm{X} 1$ & $4.25(0.75)$ & $3.85(0.89)$ & $3.86(0.95)$ & $4.27(0.73)$ & $4.40(0.65)$ & 5.996 & $.000 * * *$ \\
\hline
\end{tabular}

Note. Values are mean(standard deviation).

${ }^{\mathrm{z}} \mathrm{X} 5=$ new experience; $\mathrm{X} 6=$ improving refinement; $\mathrm{X} 8=$ high historical value; $\mathrm{X} 4=$ cultural experience; $\mathrm{X} 7=$ enjoying local cultural color; $\mathrm{X} 10=$ an event with family; $\mathrm{X} 9=$ many things to eat; $\mathrm{X} 3=$ fun programs; $\mathrm{X} 2=$ things to see; $\mathrm{X} 1=$ things to enjoy.

${ }^{\mathrm{y}} \mathrm{A}=$ below middle school; $\mathrm{B}=$ middle or high school graduate; $\mathrm{C}=2$-year college graduate; $\mathrm{D}=$ university graduate; $\mathrm{E}=$ graduate school or higher.

${ }^{\text {NS Non-significant, }}{ }^{*} p<.05,{ }^{* *} p<.01, \stackrel{* * *}{p}<.001$ by ANOVA test. 
A had the most positive perception with 5.00, followed by Group B 4.60, Group C 4.44, Group D 4.13, Group E 4.09, and Group F 3.85. This indicated that younger age groups had more positive perception about things to enjoy. This result is similar to that of Roh (2012) proving that influential factors of community members with common characteristics are important in gardens. Thus, this is an important factor for revitalizing garden events associated with image of event.

By more specifically examining education level, we could see that the participants generally perceived new experience as 'important', and by education level, Group E had the most positive perception on new experience with 4.58, followed by Group A 4.25, Group D 4.21, Group C 4.00, and Group B 3.97. Aside from Group A, groups with higher education level generally had more positive perception about new experience.

The participants perceived cultural experience as 'average' or higher, and by education level, Group E had the most positive perception about cultural experience with 4.38 , followed by Group A 4.17, Group D 4.16, Group B 3.93, and Group C 3.86. Overall, groups with higher education level generally had more positive perception about cultural experience. As for enjoying local cultural color, the participants perceived it as 'average' or higher, with Group D having the most positive perception about enjoying local cultural color with 4.19, followed by Group E 4.16, Group B 3.99, Group A 3.75, and Group C 3.68. The participants also generally perceived fun programs as 'average' or higher, and Group E had the most positive perception about fun programs with 4.24, followed by Group D 4.12, Group A 3.83, Group C 3.81, and Group B 3.77. This showed that university graduates or higher had more positive perception about enjoying cultural color or fun programs.

As for things to see at the event, the participants generally perceived them as 'important', and Group E had the most positive perception about things to see with 4.33 , followed by Group D 4.28, Group A 4.17, Group B 3.93, and Group C 3.92. They also perceived things to enjoy at the event as 'average' or higher, and Group E perceived it as 'important' with 4.40, followed by Group D 4.27, Group A 4.25, Group C 3.86, and Group B 3.85. This showed that side from Group A, groups with higher education level generally had more positive perception about things to enjoy or things to see at the event. This result is similar to that of Kang (2003) proving that the image of event selected as a cultural and art event has a great effect on satisfaction according to the level of local visitors. Thus, this is an important factor for revitalizing garden events associated with image of event.

\section{Comparison of perception between age/education level variables and evaluation item (Factor 2)}

With regard to evaluation items derived from factor analysis on necessary items for events, the perception gap depending on age and education level showed a statistically significant difference in 4 items of education level as shown in Tables 7 and 8, but the hypothesis was rejected in all items of age and thus results could not be drawn.

By more specifically examining each item of education

Table 7. Correlations between age and necessary items for garden event in Factor 2

\begin{tabular}{|c|c|c|c|c|c|c|c|c|}
\hline \multirow{2}{*}{ Item $^{z}$} & \multicolumn{6}{|c|}{ Age $^{\mathrm{y}}$} & \multirow{2}{*}{$\mathrm{F}$} & \multirow{2}{*}{ Sig. } \\
\hline & A & B & $\mathrm{C}$ & $\mathrm{D}$ & $\mathrm{E}$ & $\mathrm{F}$ & & \\
\hline X14 & $4.67(0.58)$ & $4.33(0.82)$ & $4.28(0.85)$ & $4.28(0.86)$ & $4.06(0.84)$ & $4.11(0.79)$ & 1.028 & $.40^{\mathrm{NS}}$ \\
\hline $\mathrm{X} 13$ & $5.00(0.00)$ & $4.40(0.74)$ & $4.28(0.78)$ & $4.23(0.84)$ & $4.03(0.89)$ & $4.06(0.87)$ & 1.630 & $.15^{\mathrm{NS}}$ \\
\hline $\mathrm{X} 15$ & $5.00(0.00)$ & $4.53(0.74)$ & $4.14(1.02)$ & $4.26(0.97)$ & $4.02(0.94)$ & $4.10(0.95)$ & 1.469 & $.20^{\mathrm{NS}}$ \\
\hline X11 & $5.00(0.00)$ & $4.27(1.03)$ & $4.03(1.16)$ & $4.10(1.02)$ & $3.92(1.03)$ & $3.83(1.03)$ & 1.426 & $.22^{\mathrm{NS}}$ \\
\hline $\mathrm{X} 12$ & $4.67(0.58)$ & $4.33(0.72)$ & $4.03(0.97)$ & $3.97(1.06)$ & $3.80(0.97)$ & $3.76(0.97)$ & 1.735 & $.13^{\mathrm{NS}}$ \\
\hline
\end{tabular}

Note. Values are mean(standard deviation).

${ }^{\mathrm{z}} \mathrm{X} 14=$-venue safety; X13=kind event staff; X15=adequate amenities; X11=signposts; X12=event information.

${ }^{\mathrm{y}} \mathrm{A}=$ under 20; $\mathrm{B}=21-30 ; \mathrm{C}=31-40 ; \mathrm{D}=41-50 ; \mathrm{E}=51-60 ; \mathrm{F}=$ over 60 years old.

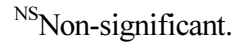


level showing a significant difference, we could find out that the participants generally perceived kindness of event staff as 'important', and by education level, Group A had the most positive perception about kindness of event staff with 4.67, followed by Group D 4.24, Group E 4.18, Group C 4.00, and Group B 3.99. They also perceived adequate amenities as generally 'important', and Group E had the most positive perception about adequate amenities with 4.38, followed by Group D 4.25, Group A 4.08, Group B 4.05, and Group C 3.78. Aside from Group A, groups with higher education level generally had more positive perception about adequate amenities. They also perceived signposts as generally 'important', and Group A had the most positive perception about signposts with 4.58 , followed by Group E 4.27, Group D 4.08, Group B 3.72, and Group C 3.68. As for event publicity, they generally perceived it as 'average' or higher, with Group A showing the most positive perception with 4.17, followed by Group D 4.07, Group E \& C 3.89 and Group B 3.64. Group A had the most positive perception on kindness of event staff, signposts, and event publicity, but aside from Group A, groups with higher education level generally had more positive perception. This result is similar to that of Roh (2012) proving that influential factors of community members with a specific goal and common characteristics are valued in gardens, and Kim (2018) proving that the ratio of perception on urban agriculture turns out to be high depending on education level. Thus, this is an important item for revitalizing garden events associated with image of event based on the premise that information accessibility may vary depending on education level.

\section{Verifying the relationship of age/education level and event items}

We tested whether the regression model is statistically suitable with the hypothesis that there will be different responses about necessary items for events depending on age and education level (Table 9). As a result of setting age and education level as dependent variables and necessary items for events as the independent variable, it was found that age had the $\mathrm{F}$ value of 5.000 and education level had

Table 8. Correlations between education and necessary items for garden event in Factor 2

\begin{tabular}{|c|c|c|c|c|c|c|c|}
\hline \multirow{2}{*}{ Item $^{\mathrm{z}}$} & \multicolumn{5}{|c|}{ Education level $^{\mathrm{y}}$} & \multirow{2}{*}{$\mathrm{F}$} & \multirow{2}{*}{ Sig. } \\
\hline & A & B & $\mathrm{C}$ & $\mathrm{D}$ & E & & \\
\hline $\mathrm{X} 14$ & $4.25(0.87)$ & $4.04(0.85)$ & $3.95(0.88)$ & $4.26(0.77)$ & $4.36(0.77)$ & 2.270 & $.06^{\mathrm{NS}}$ \\
\hline $\mathrm{X} 13$ & $4.67(0.49)$ & $3.99(0.91)$ & $4.00(0.91)$ & $4.24(0.80)$ & $4.18(0.83)$ & 2.550 & $.04 *$ \\
\hline $\mathrm{X} 15$ & $4.08(1.31)$ & $4.05(0.92)$ & $3.78(1.11)$ & $4.25(0.91)$ & $4.38(0.78)$ & 2.635 & $.03 *$ \\
\hline $\mathrm{X} 11$ & $4.58(0.67)$ & $3.72(1.04)$ & $3.68(1.03)$ & $4.08(1.08)$ & $4.27(0.92)$ & 4.685 & $.001 * * *$ \\
\hline $\mathrm{X} 12$ & $4.17(0.94)$ & $3.64(1.00)$ & $3.89(0.99)$ & $4.07(0.92)$ & $3.89(0.96)$ & 2.814 & $.03 *$ \\
\hline
\end{tabular}

Note. Values are mean(standard deviation).

${ }^{\mathrm{z}} \mathrm{X} 14=$ =venue safety; X13=kind event staff; X15=adequate amenities; X11=signposts; X12=event information.

${ }^{\mathrm{y}} \mathrm{A}=$ below middle school; $\mathrm{B}=$ middle or high school graduate; $\mathrm{C}=2$-year college graduate; $\mathrm{D}=$ university graduate; $\mathrm{E}=$ graduate school or higher.

${ }^{\mathrm{NS}}$ Non-significant, ${ }^{*} p<.05,{ }^{* * *} p<.001$ by ANOVA test.

Table 9. Regression analysis between age/education and necessary items for garden event

\begin{tabular}{|c|c|c|c|c|c|c|c|c|c|c|}
\hline \multirow{2}{*}{ Item } & \multicolumn{3}{|c|}{$\mathrm{Age}^{\mathrm{b}}$} & \multirow{2}{*}{$\mathrm{F}$} & \multirow{2}{*}{ Sig. } & \multicolumn{3}{|c|}{ Education level $^{\mathrm{c}}$} & \multirow{2}{*}{$\mathrm{F}$} & \multirow{2}{*}{ Sig. } \\
\hline & Sum of Squares & df & Mean Square & & & Sum of Squares & $\mathrm{df}$ & Mean Square & & \\
\hline Regression & 97.328 & 15 & 6.489 & 5.000 & $.000^{\mathrm{a}}$ & 42.424 & 15 & 2.828 & 2.104 & $.010^{\mathrm{a}}$ \\
\hline Residual & 365.991 & 282 & 1.298 & & & 379.052 & 282 & 1.344 & & \\
\hline Total & 463.319 & 297 & & & & 421.477 & 297 & & & \\
\hline
\end{tabular}

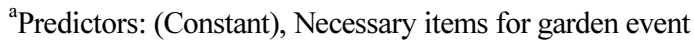

${ }^{\mathrm{b}}$ Dependent Variable: Age

${ }^{\mathrm{c}}$ Dependent Variable: Education level 
the $\mathrm{F}$ value of 2.104 , and both variables had the $p$ value lower than .05 , which proved that this regression model was suitable.

\section{Conclusion}

With the assumption that gardens are a place where not only physical activities take place but also a common topic of conversation is provided, this study proposed utilization plans of urban gardens for community revitalization by examining the role of urban gardens through activities in gardens and verifying the importance of the community.

Based on theoretical review of previous studies, we set the necessary items for events that can be applied to urban gardens. In the empirical research to test the hypothesis of the designed research model, we developed measurement items and scales to use as the variables of each construct and conducted a survey on male and female adults aged 19 and above that visited the 8th Korean Urban Agriculture Expo. Out of total 310 copies of the distributed questionnaire, only 298 effective samples were used in the final analysis. The reliability and validity of variables were proved by conducting reliability and factor analysis. To test the hypothesis, we conducted an independent samples t-test and one-way ANOVA as well as simple regression analysis and checked the significance level of each group through posteriori analysis. The results can be summarized as follows.

First, as a result of conducting reliability and validity analysis of variables measuring key items for events, 15 variables were finalized as necessary items for events. Thus, according to the result of factor analysis, two factors were named: image of event (Factor 1) and evaluation item (Factor 2).

Second, to test whether there is a difference in responses about necessary items for events depending on demographic variables, we analyzed the responses by gender, age, education level, occupation, income and residence. The results showed that there was a statistically significant difference and thus we tested the relationship between age and education level for which the research hypothesis was accepted. As a result, we found that, for Factor 1, age was significant in five items such as new experience, enjoying local cultural color, fun programs, things to see, and things to enjoy, and education level was significant in six items such as new experience, cultural experience, enjoying local cultural color, fun programs, things to see, and things to enjoy. There was a significant difference according to each variable in other items. For Factor 2, four items except venue safety such as signposts, enough information about the event, kindness of event staff, and adequate amenities were effective in relation to education level, while significant results could not be drawn in all items for age. Since the influential factors of members with a specific purpose and common characteristics are considered important in a community for gardens, it is necessary to establish clear concepts for various types of events for differentiation and plan events, select programs and carry them out according to those concepts.

Third, since gardens tend to be fixed unlike other consumer goods, it is difficult for them to provide vividness or liveliness. Considering this fact, according to Kang (2003), intangible planning and staging with characteristics of place may enable those gardens to infinitely provide diverse and vivid interest and attractiveness. Thus, holding events at gardens can produce positive effects on not only creating high added value and revitalizing the regional economy but also revitalizing the community, in addition to their current benefits. Therefore, to invite voluntary participation of garden users, it is important to have users participate from the process of forming the gardens so that the host of event planning can be the users themselves.

This study has the greatest significance in that it came up with necessary items for community revitalization of urban gardens. However, in conducting related research, it cannot sufficiently represent the garden events since it examined only visitors of the urban expo. Based on this study, it is necessary to conduct research on the use of urban gardens as an event with social functions as well as various programs that can be carried out in gardens to build and revitalize the community. 


\section{References}

Hong, I.K., Y. Chae, Y.N. Jang, S.M. Lee, and J.N. Su. 2018. Analysis of urban agricultural effects by factors according to the urban citizens income level: Socially sustainable effect, negative effect, and economically sustainable effect. J. People Plants Environ. 21(6):461-471. https://doi.org/10.11628/ksppe.2018.21.6.461

Im, M.J. 2011. A perception survey on the users of urban gardens for local community vitalization. Master's thesis, Seoul Women's University, Seoul, Korea.

Kang, J.H. 2016. Step by step guide to statistical analysis by using the new spss program. Seoul, Korea: Crownbook Press.

Kang, K.N., J.K. Lee, K.H. Kim, and M.H. Lee. 2007. Revitalization planning of urban farming based on vegetable gardens. J. Inst. Constr. Technol. [Chungbuk National University] 26(1):167-176.

Kang, S.G. 2003. The influence of pre-image and post-im- age of tourism event upon visitors'satisfaction and recommendation intention. Doctoral dissertation, Dong-A University, Busan, Korea.

Kim, H.R. 2018. A study on the perception of and satisfaction with urban farming management. Doctoral dissertation, Chonbuk National University, Jeonju, Korea.

Kim, S.B., J.H. Cho, and E.H. Jung. 2002. Environmental friendly cities and urban agriculture. J. Inst. Constr. Technol. [Chungbuk National University] 7(1):71-91.

Lee, D.G. 2013. A study of the preference on the type of urban agriculture and activity preferences by lifestyle. Master's thesis, Hanyang University, Seoul, Korea.

Lee, P.Y. 2003. Understanding of methods of sampling and analysis in statistics. Paju, Korea: Free Academy.

Roh, H.Y. 2012. A study on the influencing factors of urban community garden for the activation of community. Master's thesis, Seoul National University, Seoul, Korea. 